\section{A FAST COMPARISON OF IR-SPECTRA FOR SCREENING NEW ANTIBIOTICS}

\section{G. Strauss}

Akademie der Wissenschaften der DDR, Forschungszentrum für Molekularbiologie und Medizin, Zentralinstitut für Mikrobiologie und Experimentelle Therapie

Beuthenbergstr. 11, Jena 69, DDR

(Received for publication February 18, 1974)

Rapid, efficient screening of new antibiotics depends on quick determination of similarity or identity with earlier-described materials. The infra-red spectrum contains a wealth of specific information and comparison of spectra should be a useful tool at an early stage of investigation. However, there are several difficulties with using all the information in the IR spectrum. If peak position only is used, there is considerable confusion between compounds with similar functional groups. Multiple functional groups give rise to overlap.

For maximum information the entire spectrum must be used but this causes difficulties in presenting the data. The new procedure described here is based on the concept that the position and intensity of the individual peaks relative to each other reflect the structural character of the molecule. The spectrum is divided into small portions and the character of each segment indicated by a numer-

Table 1

\begin{tabular}{c|c|c}
\hline MRD & $\mathrm{cm}^{-1}$ & micrometres \\
\cline { 2 - 3 } 2 & $3700 \sim 3030$ & $2.70 \sim 3.29$ \\
2 & $3030 \sim 2700$ & $3.30 \sim 3.69$ \\
3 & $2700 \sim 1820$ & $3.70 \sim 5.49$ \\
4 & $1818 \sim 1669$ & $5.50 \sim 5.99$ \\
5 & $1667 \sim 1540$ & $6.00 \sim 6.49$ \\
6 & $1538 \sim 1430$ & $6.50 \sim 6.99$ \\
7 & $1429 \sim 1335$ & $7.00 \sim 7.49$ \\
8 & $1333 \sim 1252$ & $7.50 \sim 7.99$ \\
9 & $1250 \sim 1178$ & $8.00 \sim 8.49$ \\
10 & $1175 \sim 1110$ & $8.50 \sim 8.99$ \\
11 & $1111 \sim 1055$ & $9.00 \sim 9.49$ \\
12 & $1053 \sim 1000$ & $9.50 \sim 9.99$ \\
13 & $1000 \sim 910$ & $10.00 \sim 10.99$ \\
14 & $910 \sim 800$ & $11.00 \sim 12.49$ \\
15 & $800 \sim 700$ & $12.50 \sim 14.50$ \\
\hline
\end{tabular}

ical code. These codes are then used for comparison purposes either manually or by computer.

First, the IR curve from $700 \mathrm{~cm}^{-1}$ to 3700 $\mathrm{cm}^{-1}$ is divided into 15 measuring range divisions (MRD) as shown in Table 1.

Next, the character of the curve in each MRD is determined and recorded as a two digit number. The first or 10's digit represents the relative intensities of the peaks or the general shape of the curve in the MRD as shown by Table 2. The second (units) digit is the number of peaks in the MRD. Examples of code assignment are given in Figs. $1 \sim 3$.

By this method the entire spectrum represented by 15 two-digit number which can be obtained from published spectra as well as experimental spectra. The evaluation and code assignment can be manual or by computer. An example of a code list from the computer is shown in Table 3 .

The comparison of two antibiotics can be accomplished in the computer by coding and then adding the new code to the file after it has been compared with all the other spectra on file.

Two spectra in coded form are compared by first determining the difference in the code for each MRD. These differences (absolute values) are added to give a total which is

Table 2

\begin{tabular}{|c|c|c|c|c|c|c|c|c|c|c|}
\hline & & & Тyp & & & & & & & Code \\
\hline $\begin{array}{l}\text { A) asce } \\
\text { peak }\end{array}$ & din & & $\begin{array}{l}\mathrm{cm}^{-} \\
\text {ties }\end{array}$ & & alu & ies & & scending & & 10 \\
\hline B) & $" / \mathrm{a}$ & alte & erna & tin & & & " & & & 30 \\
\hline C) & 110 & des & cenc & din & & & " & & & 50 \\
\hline D) & $\| / 0$ & cur & ve $n$ & $\min$ & him & un & $n$, & no peak & & 40 \\
\hline $\begin{array}{l}\text { Zero in } \\
\text { this } \mathrm{N}\end{array}$ & & & & & & & & eans no & & in \\
\hline & Tab & le & 3. & $\mathrm{~Pa}$ & rt & of & 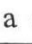 & code-list & & \\
\hline & & & & & & & & MRD & & \\
\hline Address & 1 & 2 & \begin{tabular}{l|l}
3 & 4
\end{tabular} & 45 & 6 & 7 & 8 & \begin{tabular}{|l|l|l|l|}
9 & 10 & 11 & 12
\end{tabular} & $13 \mid 14$ & 15 \\
\hline $000 \quad 072$ & 34 & & 125 & 013 & 352 & 53 & 51 & \begin{tabular}{ll|l|l|l|l|l|l|l|l|l|l|l|}
33 & 12 & 52
\end{tabular} & 3453 & 52 \\
\hline $000 \quad 074$ & 51 & & 111 & 151 & 11 & 51 & 51 & 11324052 & 1051 & 32 \\
\hline $000 \quad 077$ & 51 & & 301 & 111 & 11 & 52 & 51 & \begin{tabular}{l|l|l|l|l|l|l|l|l|}
51 & 12 & 52 & 11
\end{tabular} & 1112 & 32 \\
\hline $000 \quad 080$ & 51 & & 123 & 233 & 311 & & & $\begin{array}{lllll}11 & 12 & 11 & 40\end{array}$ & 3352 & 12 \\
\hline $000 \quad 083$ & 11 & & 301 & 151 & 11 & & & $13 \quad 5252$ & 1235 & 52 \\
\hline
\end{tabular}


termed the curve difference sum (CDS). If the two codes for a given MRD differ by more than 21, a variation in character and number of peaks is indicated for that MRD. Such cases (code difference for single MRD> 21) are counted and the total of such cases is termed the "number of limit-exceeding differences" (NLD). These indications of variation are expressed as a quantity in which the NLD is expressed as a thousands quantity,
Table 4. Computerised data on request: comparison adriamycin and other anthracyclines.

\begin{tabular}{|c|c|}
\hline NLD, CDS & Substance \\
\hline 3.125 & $\begin{array}{l}\text { Leukaemomycin } \mathrm{C} \\
\quad \text { (identical with daunomycin) }\end{array}$ \\
\hline 3.145 & Dihydrodaunomycin \\
\hline 2.145 & Rubomycin $C$ \\
\hline 3.126 & Leukaemomycin D \\
\hline 1.102 & Daunomycinon \\
\hline
\end{tabular}

Fig. 1
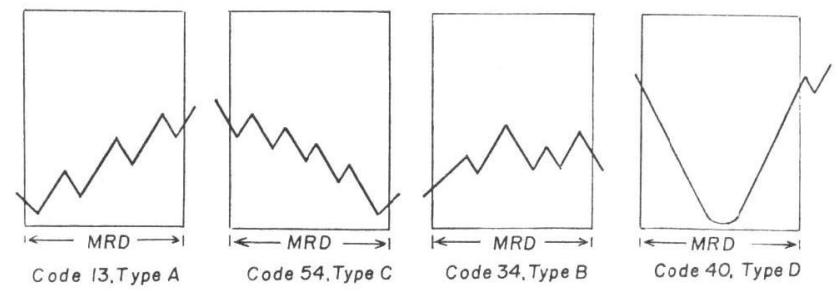

Fig. 2
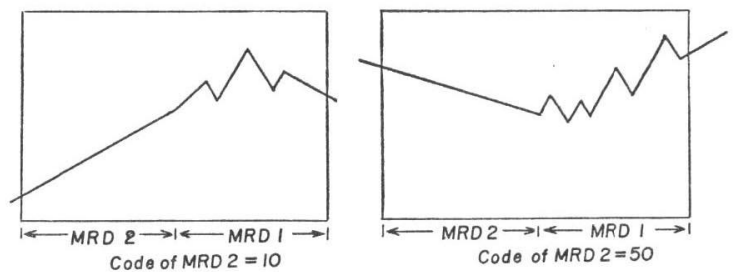

Fig. 3
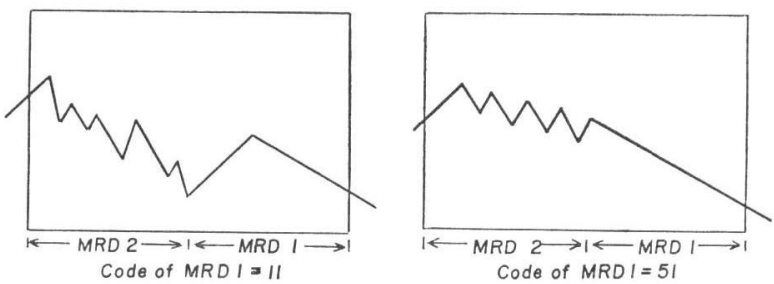

followed by three digits for the CDS as shown in Table 4. The CDS and NLD values are both used in determining similarity of two spectra.

For manually evaluated curves a value of NLD not greater than 3 and CDS not greater than 150 indicates similar or identical substances. A comparison of available data gives the following results:

$$
\begin{array}{cl}
\text { NLD, CDS values } & \text { Interpretation } \\
0,000 \sim 1,150 & \text { probable identity } \\
1,150 \sim 3,150 & \text { similarity } \\
3,150 \sim 4,150 & \text { probable similarity } \\
>4,150 & \text { different substances }
\end{array}
$$

Examples of comparison tabulations are given in next page with data from our measurements.

Values taken from the literature may be used as shown in Example 4 which compares siomycin $(\mathbf{I})^{3)}$, sporangiomycin (II) ${ }^{4)}$ and mutabilicin (III) ${ }^{5)}$.

Since the original data were published Frolova has reported the identity of $\mathbf{I}$ and III $^{8)}$ and of II and III $^{\text {7) }}$.

Example 5 involves the following group of antibiotic: $\quad$ BY-81 $(\mathbf{I V})^{8)}$, citromycin $(\mathbf{V})^{9)}$, E-749-C (VI) ${ }^{10)}$, and LL-AC-541 (VII). ${ }^{11)}$

Meanwhile TANIYAMA et al. ${ }^{12)}$ have reported 
Example 1. Comparison between ir-spectra of chartreusin ${ }^{1)}$ and lambdamycin ${ }^{2)}$

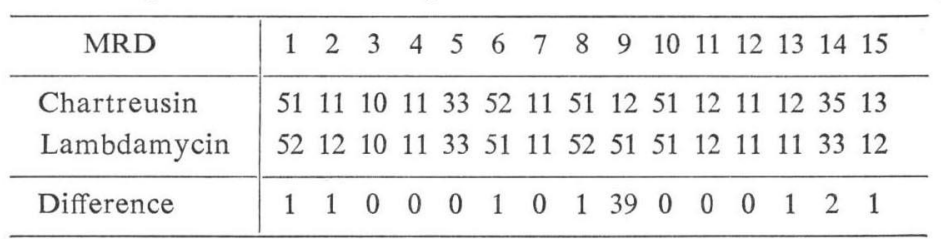

CDS: 45. NLD: 1 . Computer written: 1.045

Example 2. Comparison between ir-spectra of lambdamycin and lambdamycinon ${ }^{2)}$

\begin{tabular}{l|ccccccccccccccc}
\hline \multicolumn{1}{c|}{ MRD } & 1 & 2 & 3 & 4 & 5 & 6 & 7 & 8 & 9 & 10 & 11 & 12 & 13 & 14 & 15 \\
\hline Lambdamycin & 52 & 12 & 10 & 11 & 33 & 52 & 11 & 52 & 51 & 51 & 12 & 11 & 11 & 33 & 12 \\
Lambdamycinon & 33 & 13 & 10 & 52 & 33 & 33 & 12 & 53 & 12 & 52 & 12 & 11 & 13 & 34 & 12 \\
\hline Difference & 19 & 1 & 0 & 41 & 0 & 19 & 1 & 1 & 39 & 1 & 0 & 0 & 2 & 1 & 0 \\
\hline
\end{tabular}

CDS: 125. NLD: 2. Computer written; 2.125.

Example 3. Comparison between ir-spectra of chartreusin ${ }^{1)}$ and lambdamycinon ${ }^{2)}$

\begin{tabular}{l|ccccccccccccccc}
\hline \multicolumn{1}{c|}{ MRD } & 1 & 2 & 3 & 4 & 5 & 6 & 7 & 8 & 9 & 10 & 11 & 12 & 13 & 14 & 15 \\
\hline Chartreusin & 51 & 11 & 10 & 11 & 33 & 52 & 11 & 51 & 12 & 51 & 12 & 11 & 12 & 35 & 13 \\
Lambdamycinon & 33 & 13 & 10 & 52 & 33 & 33 & 12 & 53 & 12 & 52 & 12 & 11 & 13 & 34 & 12 \\
\hline Difference & 18 & 2 & 0 & 41 & 0 & 19 & 1 & 2 & 0 & 1 & 0 & 0 & 1 & 1 & 1 \\
\hline
\end{tabular}

CDS: 87. NLD: 1. Computer written; 1.087

Example 4.

\begin{tabular}{|c|c|c|c|c|c|c|c|c|c|c|c|c|c|c|c|}
\hline \multirow{2}{*}{ Subst. } & \multicolumn{15}{|c|}{ MRD } \\
\hline & & 2 & 3 & 4 & 5 & 6 & 7 & 8 & 9 & 10 & 11 & & 13 & 14 & \\
\hline I & 51 & 12 & 10 & 51 & 13 & 32 & 52 & 50 & 52 & 53 & 11 & 11 & 33 & & 53 \\
\hline II & 51 & 11 & 10 & 51 & 12 & 33 & 52 & 51 & 52 & 53 & 12 & 11 & 34 & 12 & 32 \\
\hline III & 51 & 12 & 10 & 51 & 11 & 32 & 52 & 52 & 52 & 53 & 11 & & 52 & 12 & 11 \\
\hline I - II & 0 & 1 & 0 & 0 & 1 & 1 & 0 & 1 & 0 & 0 & 1 & 0 & 1 & 0 & 21 \\
\hline I-III & 0 & 0 & 0 & 1 & 2 & 0 & 0 & 2 & 0 & 0 & 0 & 1 & 19 & 0 & 42 \\
\hline II - III & 0 & 1 & 0 & 0 & 1 & 1 & 0 & 1 & 0 & 0 & 1 & 1 & 18 & 0 & 21 \\
\hline
\end{tabular}

NLD. CDS $\mathbf{I}-\mathbf{I I}=1.027 ; \quad \mathbf{I}-\mathbf{I I I}=1.067 ; \quad \mathbf{I I}-\mathbf{I I I}=1.045$. Conclusion:

I, II and III are probably identical.

Example 5. IR-Comparison

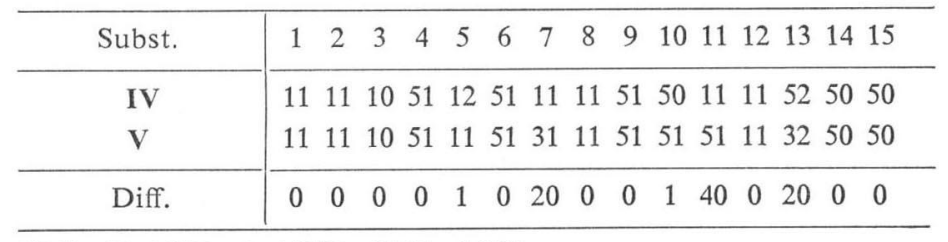

CDS: 82. NLD. 1. NLD, $\mathrm{CDS}=1.082$

Statement: Probably identical 
the identity of $\mathbf{V}$ and VII.

From the above it can be seen that this method should be of use in the quick evaluation of related materials obtained in a screening program. It offers an objective, computer-usable method to evaluate IR curves according to the general character of the curve.

\section{Acknowledgement}

Thanks are expressed to U. FröHLICH and I. StRauss for technical assistance.

\section{References}

1) Leach, B. E.; K. M. Calhoun, L. E. JohnSON, C. M. TeEters \& W. G. JACKSON: Chartreusin, a new antibiotic produced by Streptomyces chartreusis, a new species. J. Am. Chem. Soc. 75: 4011 4012, 1953

2) Fleck, W. F.; D. G. Strauss, H. Prauser, W. Jungstand, H. Heinecke, W. Gutsche \& K. Wohlrabe: DDR Pat. in press

3) Nishimura, H.; S. Окаmoto, M. Mayama, H. Ohtsuka, K. Nakajima, K. Tawara, M. Shimohira \& N. Shimaoka: Siomycin, a new thiostrepton-like antibiotic. J. Antibiotics, Ser. A 14: 255 263, 1961

4) Thiemann, J. E.; C. Coronelli, H. Pagani, G. Beretta, G. Tamoni \& V. Arioli: Antibiotic production by new form-genera of the actinomycetales. I. Sporangiomycin, an antibacterial agent isolated from Planomonospora parontospora var. antibiotica var. nov. J. Antibiotics $21: 525 \sim 531,1968$
5) Frolova, V. I.; E. P. Yulikova, A. D. Kuzovkov \& E. F. Oparysheva: Isolation and characterization of mutabilicin (21-31), a new antibacterial antibiotic. Antibiotiki $11: 887 \sim 892,1966$

6) Frolova, V. I.; G. S. Kaurukha \& A. D. Kuzovkov: Identification of antibacterial antibiotics, mutabilicin and sporangiomycin. Antibiotiki $16: 204 \sim 207,1971$

7) Frolova, V. I. ; S. M. Rudaya, G.S. KATRUKHA \& A.D. KuzovKov: Isolation and identification of thiostrepton and mutabilicin. Antibiotiki $17: 707 \sim 710,1972$

8) Ito, Y.; Y. Ohashi, Y. Sakurai, M. Sakurazawa, H. Yoshida, S. Awataguchi \& T. OKudA: New basic water-soluble antibiotics BD-12 and BY-81. II. Isolation, purification and properties. J. Antibiotics $21: 307 \sim 312,1968$

9) Kusakabe, Y.; Y. Yamauchi, C. Nagatsu, H. Abe, K. Akasaki \& S. Shirato: Citromycin, a new antibiotic. I. Isolation and characterization. J. Antibiotics 22:112 118, 1969

10) Shoji, J.; S. Kozuki, M. Ebata \& H. OTsuka: A water-soluble basic antibiotic E-749-G identical with LL-AC541. J. Antibiotics $21: 509 \sim 511,1968$

11) Borders, D. B.; W. K. Hausmann, E. R. Wetzel \& E. L. Patterson: Partial structure of antibiotic LL-AC541. Tetrahedron Letters 1969-42: 4187 4192, 1967

12) TaniYama, H. \& Y. Sawada: The identity of citromycin with LL-AC541, E-749-C, and BY-81. J. Antibiotics $24: 708 \sim 710,1971$ 